\title{
Decadal and Interdecadal Variations of the Aleutian Low Activity and Their Relation to Upper Oceanic Variations over the North Pacific
}

\author{
Shusaku SUGIMOTO \\ Department of Geophysics, Graduate School of Science, Tohoku University, Sendai, Japan \\ and \\ Kimio HANAWA \\ Department of Geophysics, Graduate School of Science, Tohoku University, Sendai, Japan \\ (Manuscript received 12 November 2008, in final form 12 March 2009)
}

\begin{abstract}
Long-term variations of the Aleutian Low (AL) defined by the sea level pressure (SLP) minimum within the region of $\left[30^{\circ} \mathrm{N}-60^{\circ} \mathrm{N}, 150^{\circ} \mathrm{E}-150^{\circ} \mathrm{W}\right]$ during winter (December-February) are investigated, using atmospheric reanalysis datasets. The intensity, latitudinal position, and longitudinal position of AL reveal different temporal variations: the longitudinal shift accompanies intensity variation with an interdecadal timescale (about 20 years), and the latitudinal shift does with a decadal timescale (about 10 years). The AL intensity variation and the longitudinal shift are related to activity of the Pacific/North American teleconnection pattern: in a strengthening (weakening) phase of AL, the AL shifts eastward (westward); westerlies strengthen (weaken), and both subtropical and subpolar gyres spin-up (spin-down) simultaneously. The latitudinal shift is associated with activity of the West Pacific teleconnection pattern. It is independent of the intensity variation of AL: when the AL shifts northward (southward), the westerlies correspondingly move northward (southward). Consequently, the gyre boundary, which is defined by the zero line of the Sverdrup stream function, also shifts northward (southward).

The role of AL north-south shift on the upper oceanic variations is investigated by using a wind-driven hindcast model. The oceanic Rossby wave formed as a result of the baroclinic response for the AL movement influences the sea surface temperature in the Kuroshio-Oyashio Extension region.
\end{abstract}

\section{Introduction}

The wintertime Aleutian Low (AL) activity is known to affect the atmospheric and oceanic states in the North Pacific sector strongly and in various ways (Nitta and Yamada 1989; Trenberth 1990). One dominant long-term variation of AL is apparent in its intensity. Numerous authors have

Corresponding author: Shusaku Sugimoto, Department of Geophysics, Graduate School of Science, Tohoku University, 6-3 Aramaki-aza-Aoba, Aoba-ku, Sendai 980-8578, Japan.

E-mail: sugimoto@pol.gp.tohoku.ac.jp

(C) 2009, Meteorological Society of Japan described that the intensity of AL has a considerable interdecadal time scale variation (20 years or longer; Minobe 1997, 1999; Overland et al. 1999) and shows a substantial trend over the last 50 years (Raible et al. 2005). Several reports have described correspondence between the intensity variation and longitudinal movement of AL central position (Hanawa et al. 1989; Overland et al. 1999; Rodionov et al. 2005). The AL activity strongly affects the sea surface temperature (SST) variation (Latif and Barnett 1996), marine ecosystems (Ebbesmeyer et al. 1991; Polovina et al. 1995; Mantua et al. 1997), and the change in magnitude of the subtropical and subpolar gyres (Ishi and Hanawa 2005; Yasuda and Sakurai 2006). In fact, the AL activity 
is a primary cause of long-term variations of the atmospheric and oceanic states in the North Pacific.

As indicators of the AL activity, two major indices have been used in various studies to date: the North Pacific Index (NPI: Trenberth and Hurrell 1994), which is defined as the sea level pressure (SLP) averaged within the area of $\left[30^{\circ} \mathrm{N}-65^{\circ} \mathrm{N}\right.$, $\left.160^{\circ} \mathrm{E}-140^{\circ} \mathrm{W}\right]$; and the Aleutian Low pressure Index (ALPI: Beamish et al. 1997), which is defined as the area (unit of millions of square kilometers) of the AL pressure system with pressure of less than $1005 \mathrm{hPa}$. Although these indices capture the intensity variation of AL well, whether or not these indices can represent the change in location of $\mathrm{AL}$ adequately remains unclear. It is inferred that the change in the location of AL might also impart strong impacts on the upper oceanic field, such as variations of surface current system and shift of the gyre boundary. For that reason, it is necessary to reveal roles of change in location of AL for additional understanding of upper oceanic variations in the North Pacific.

This study is undertaken to investigate temporal variations of $\mathrm{AL}$ activity in terms of intensity and location (latitudinal and longitudinal position). Furthermore, we relate them to activities of the atmospheric teleconnection patterns because they repeatedly force the upper oceanic field with organized patterns (e.g., Ishi and Hanawa 2005). The remainder of this paper is organized as follows. Section 2 presents a description of datasets and methods. In Section 3, temporal behaviors of AL are investigated, and relationships between the AL and teleconnection patterns are explored. In Section 4, roles of AL activity on the upper ocean field are discussed. Section 5 presents our summary and remarks.

\section{Datasets and methods}

We use two SLP datasets to extract behaviors of AL robustly: the National Centers for Environmental Prediction/National Center of Atmospheric Research (NCEP/NCAR) reanalysis dataset (NRA; Kalnay et al. 1996) on a $2.5^{\circ}$ latitude $\times 2.5^{\circ}$ longitude grid and the European Center for Medium range Weather Forecasting (ECMWF) 40-year reanalysis dataset (ERA; Uppala et al. 2005) on a $2.5^{\circ}$ latitude $\times 2.5^{\circ}$ longitude grid. In the present study, a central position of AL is defined as a place where SLP takes a minimal value within a region of $\left[30^{\circ} \mathrm{N}-60^{\circ} \mathrm{N}, 150^{\circ} \mathrm{E}-\right.$ $\left.150^{\circ} \mathrm{W}\right]$ in winter mean field (December-February).
As two minimal values were detected at three years (1956, 1971, and 1982), we adopted a place with SLP minimum as a central position. In this study, the behaviors (intensity and location) at the central position are investigated. Two wind stress datasets are also obtained from the NRA and ERA. Because wind stress curl (WSC) is calculated by the spatial derivative of wind stress, small-scale features tend to be exaggerated. To highlight the large-scale variations, we use the WSC field adopted four times by a 1-2-1 filter in the zonal and meridional directions. Consequently, the half power point of this filter is about $2000 \mathrm{~km}$. In the following sections, we show only the results obtained using the NRA because almost identical results are obtained from the ERA. We also use the National Oceanic and Atmospheric Administration Extended Reconstructed SST (NOAAERSST) dataset (Smith and Reynolds 2004) on a $2^{\circ}$ latitude $\times 2^{\circ}$ longitude. In this study, we focus on winter mean field (December-February) in the North Pacific $\left[10^{\circ} \mathrm{N}-60^{\circ} \mathrm{N}, 120^{\circ} \mathrm{E}-120^{\circ} \mathrm{W}\right]$, which includes both subtropical and subpolar gyres. The analysis period is the 57 years of 1950-2006. In correlation analyses, a significance level is determined using the degrees of freedom calculated using Davis (1976) method.

As an indicator of the AL intensity, we use two indices-NPI and ALPI - the time series of which are depicted in Figs. 1a, b. Here, the sign of NPI is reversed from that of the original index, to interpret strengthening or weakening of AL activity easily,
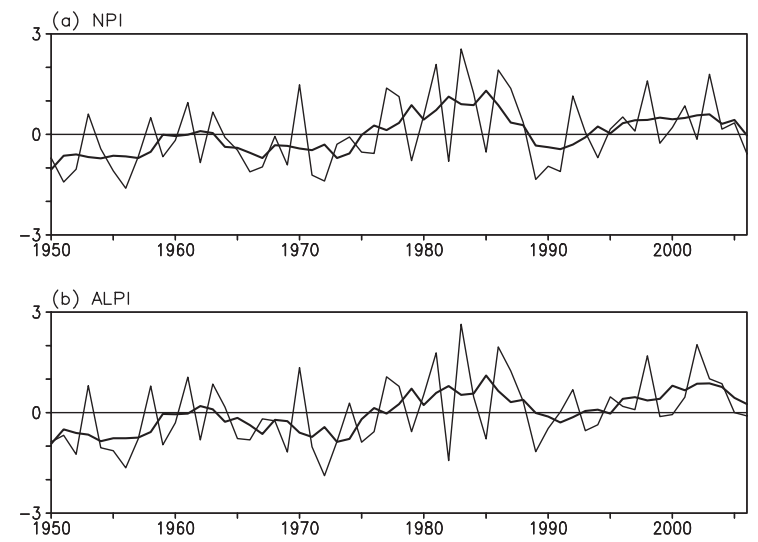

Fig. 1. Time series of normalized (a) NPI and (b) ALPI. The sign of NPI is reversed. The thick line shows the 5-year running mean. 

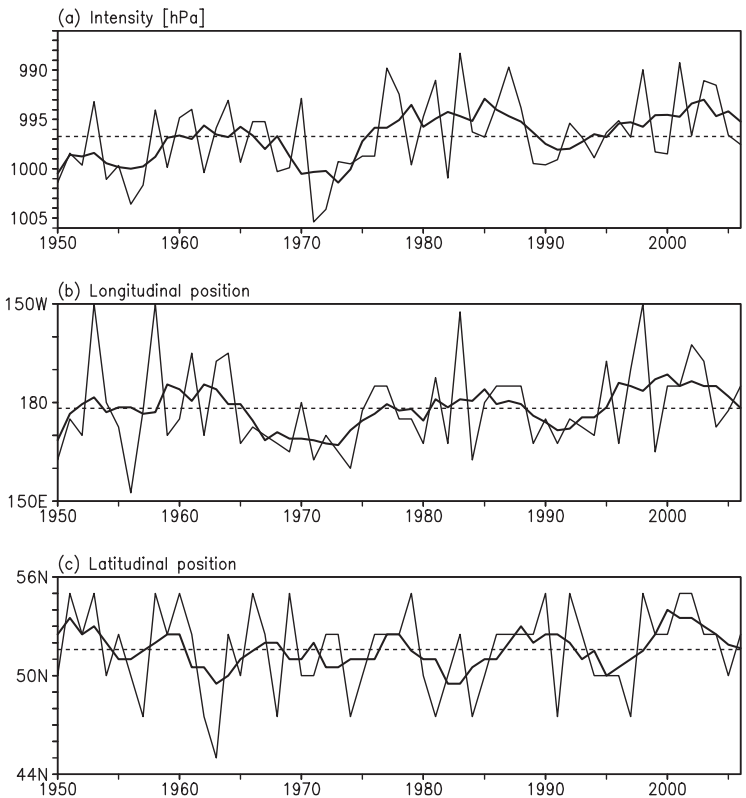

Fig. 2. Time series of (a) intensity, (b) longitudinal position, and (c) latitudinal position of AL. Thick line shows the 5-year running mean. The horizontal dashed line denotes the mean value: (a) $996.7 \mathrm{hPa}$, (b) $178.2^{\circ} \mathrm{E}$, and (c) $51.6^{\circ} \mathrm{N}$.

i.e., the positive (negative) sign of the index means the strengthening (weakening) phase of the AL. We investigate a relation between the AL activity and atmospheric teleconnection patterns. Up to date, two major approaches have been used to obtain a teleconnection pattern index: a teleconnection analysis (one-point correlation analysis; examples are seen in Wallace and Gutzler 1981) and a rotated empirical orthogonal function (REOF) analysis (Barnston and Livezey 1987). In the following sections, we show only results using teleconnection pattern indices of Barnston and Livezey (1987), because almost identical results were obtained using the indices of Wallace and Gutzler (1981). The indices of nine patterns detected in the Northern Hemisphere during winter are used: the North Atlantic Oscillation (NAO), the East Atlantic pattern (EA), the West Pacific pattern (WP), the East Pacific/North Pacific pattern (EP/NP), the Pacific/North American pattern (PNA), the East Atlantic/West Russian pattern (EA/WR), the Scandinavia pattern (SCA), the Tropical/Northern Hemisphere pattern (TNH), and the Polar/Eurasia pattern (POL).
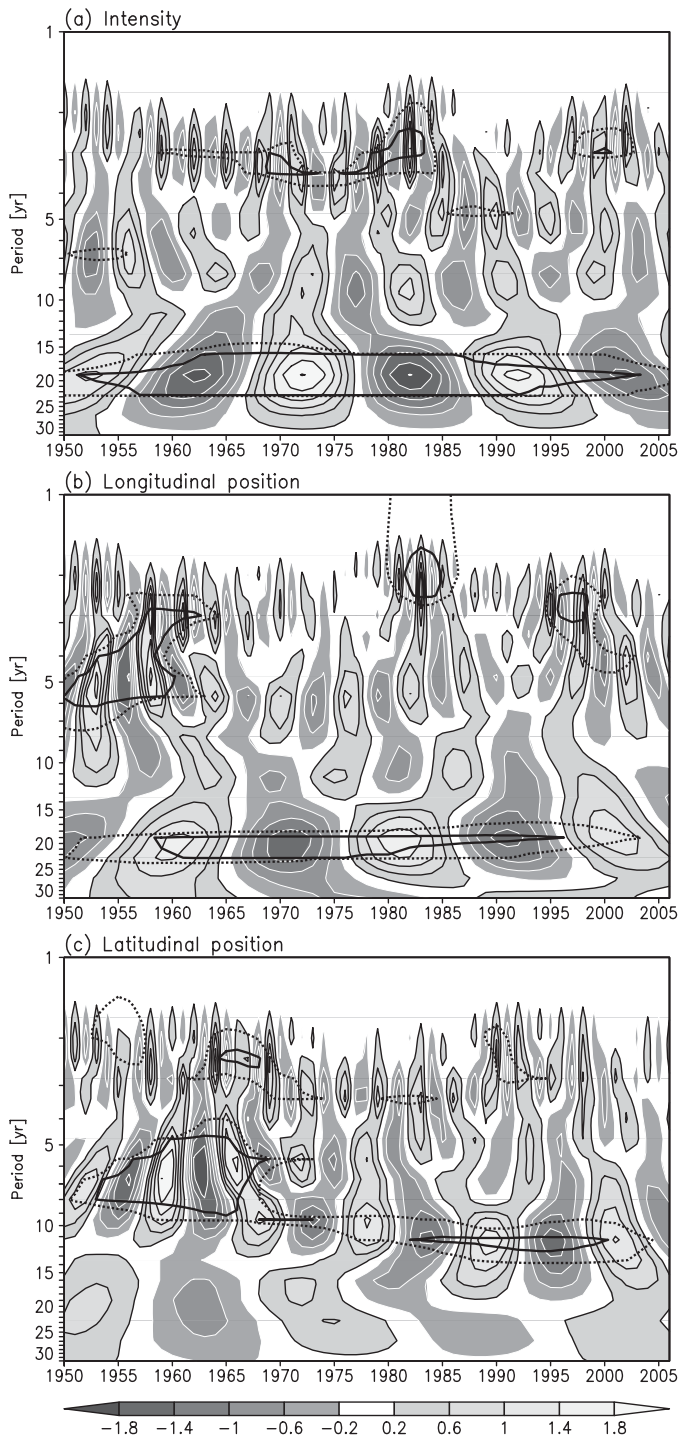

Fig. 3. The Morlet wavelet transform coefficient for normalized time series of (a) intensity, (b) longitudinal position, and (c) latitudinal position of AL. Shading indicates the amplitude of the real part of the wavelet coefficient. The black-dashed and black-solid lines show that the local wavelet spectra, which are defined as the square of the absolute wavelet transform coefficient, are significant, respectively, at 5\% and $1 \%$ significance levels. The significance level of the wavelet amplitude is evaluated using a Monte Carlo simulation based on a red-noised (AR-1) model for the observed lag-1 correlation coefficient using a 10000 surrogate time series. 
Table 1. Correlation coefficients of NPI, ALPI, and nine teleconnection pattern indices, to winter time series of intensity, longitudinal position, and latitudinal position of AL. The sign of the intensity time series is reversed for the same reason as that of NPI. Bold typeface numerals mean those exceeding a $1 \%$ significance level $(+/-0.47)$.

\begin{tabular}{|c|c|c|c|c|c|c|c|c|c|c|c|}
\hline & \multicolumn{2}{|c|}{ Indices } & \multicolumn{9}{|c|}{ Teleconnection Patterns } \\
\hline & NPI & ALPI & PNA & WP & NAO & EA & $\mathrm{EP} / \mathrm{NP}$ & EA/WR & SCA & $\mathrm{TNH}$ & POL \\
\hline Intensity & 0.84 & 0.84 & 0.85 & 0.29 & -0.02 & 0.28 & 0.13 & 0.02 & 0.02 & -0.15 & -0.12 \\
\hline Longitudinal position & 0.63 & 0.68 & 0.66 & 0.24 & -0.04 & 0.13 & 0.03 & 0.23 & -0.12 & -0.17 & -0.02 \\
\hline Latitudinal position & -0.02 & 0.06 & 0.06 & 0.74 & -0.12 & 0.27 & -0.14 & 0.30 & 0.08 & -0.32 & -0.07 \\
\hline
\end{tabular}

\section{Temporal behaviors of $\mathrm{AL}$}

\subsection{Long-term variation in terms of intensity and location}

The intensity time series of AL (Fig. 2a) shows a positive trend $(0.86 \mathrm{hPa} /$ decade $)$, which exceeds a $1 \%$ significance level by the Mann-Kendall trend test (Kendall 1938); it has significant interdecadal variations (about 20 years; Fig. 3a), as shown by Minobe (1999) and Raible et al. (2005). As expected, this time series has a high correlation with both NPI and ALPI (Table 1).

The longitudinal position time series (Fig. 2b) shows the existence of east-west shift with a longterm period. This shift ranges by about $20^{\circ}$ in longitude: eastern locations in the early 1960s, 1980s, and early 2000 s, then western locations in the early 1970s, and early 1990s. This time series also shows a dominant signal with the interdecadal timescale of about 20 years (Fig. 3b); it has a significant correlation with the intensity time series $(R=0.66)$, NPI and ALPI (Table 1): the longitudinal shift is accompanied with the intensity variation, as described by Hanawa et al. (1989) and Overland et al. (1999). The AL strengthens (weakens) concomitantly according to the AL location east (west) in longitude.

The latitudinal position time series (Fig. 2c) also shows the existence of a long-term north-south shift ranging approximately $10^{\circ}$ in latitude. Surprisingly, not interdecadal-scale variations but decadalscale variations (about 10 years) are observed: the period is $8-11$ years (Fig. 3c). This latitudinal shift is independent of the intensity variations. Actually, the correlation coefficient between them is only 0.15 . Furthermore, this latitudinal shift has no correlation with NPI or ALPI (Table 1). For that reason, we can emphasize that neither the NPI nor ALPI used in the previous works includes any information related to the latitudinal shift.
We defined the central position of AL using the SLP dataset on a $2.5^{\circ}$ latitude $\times 2.5^{\circ}$ longitude. It cannot be said that we succeeded in detecting the proper position in a strict sense because the spatial resolution is roughish. However, the temporal variations of AL in terms of location had large amplitude: about $10^{\circ}$ in the meridional direction and $30^{\circ}$ in the zonal direction. Therefore, it can be concluded that the spatial resolution of dataset used in this study is sufficient to investigate variations in the location of $\mathrm{AL}$.

\subsection{Relation with teleconnection patterns}

The temporally variable atmospheric circulation has prevailing organized disturbances called 'teleconnection patterns' (Wallace and Gutzler 1981). We investigate a relation between the AL variations and the teleconnection patterns. The AL latitudinal position variation well corresponds to the WP pattern (see Table 1). Moreover, the variation of AL intensity (and AL longitudinal position) shows a strong correlation with the PNA pattern, as pointed out by Trenberth and Hurrell (1994). These indices are displayed in Fig. 4.

We perform a regression analysis to confirm the relation described above from the viewpoint of a spatial pattern. Figure 5 depicts results in the North Pacific $\left[20^{\circ} \mathrm{N}-90^{\circ} \mathrm{N}, 90^{\circ} \mathrm{E}-90^{\circ} \mathrm{W}\right]$ because significant signals do not exist in the North Atlantic. In the regression map of SLP anomaly field for the intensity time series (Fig. 5a), a positive anomaly appears around the Aleutian Islands. The center of action is situated around $\left[50^{\circ} \mathrm{N}, 165^{\circ} \mathrm{W}\right]$. This pattern coincides excellently with that for the PNA index (Fig. 5c). Additionally, we were able to obtain the almost identical spatial pattern from the longitudinal position time series (not shown here). The map for the latitudinal position time series shows the north-south dipole pattern, whose boundary lies along the latitude of about $50^{\circ} \mathrm{N}$ (Fig. 5b). The 

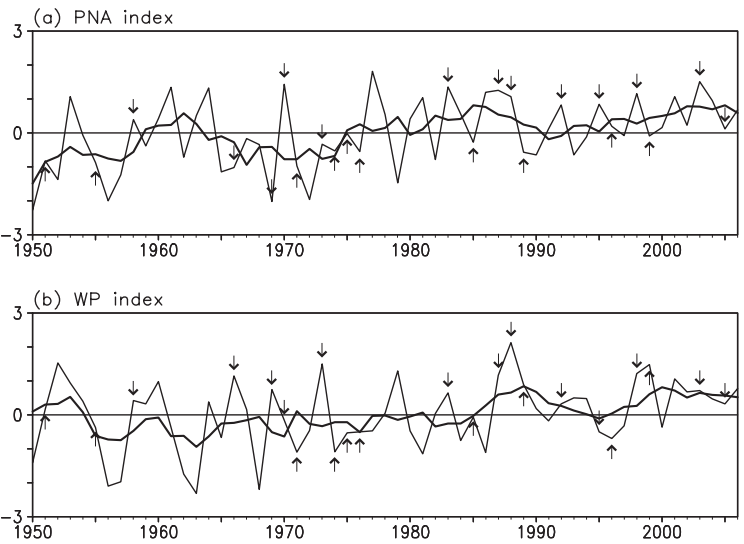

Fig. 4. Time series of normalized (a) PNA and (b) WP index. The thick line shows the 5-year running mean. Downward (upward) arrows indicate the years during which the El Niño (La Niña) events occurred.

centers of action are situated around $\left[60^{\circ} \mathrm{N}, 170^{\circ} \mathrm{W}\right]$ in the positive area and $\left[35^{\circ} \mathrm{N}, 170^{\circ} \mathrm{W}\right]$ in the negative area, which is consistent with that for the WP index (Fig. 5d) and which resembles the North Pacific Oscillation pattern defined as a second em-

(a) Intensity vs. SLP

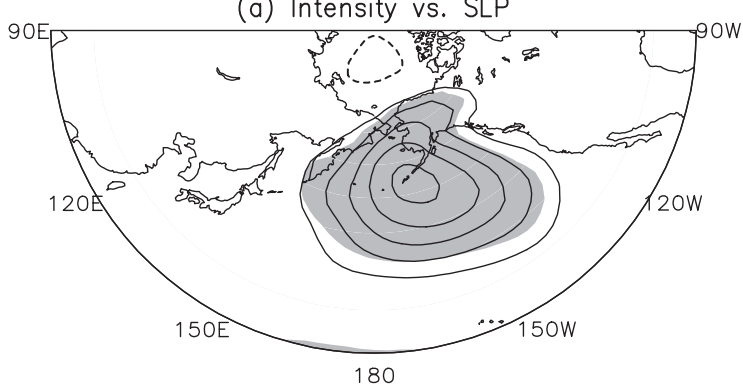

(c) PNA vs. SLP

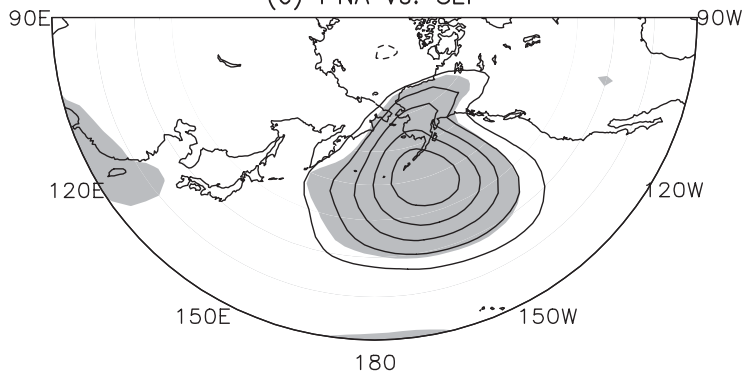

pirical orthogonal function (EOF) mode of winter North Pacific SLP anomaly field (Walker and Bliss 1932; Rogers 1981).

The correlation coefficient between the PNA and WP index is small $(R=0.19)$. Actually, it might be said that these patterns are mutually independent: the longitudinal shift accompanying intensity variation with the interdecadal timescale and latitudinal shift with the decadal timescale are therefore regarded respectively as having completely independent patterns of variation.

\subsection{Relation with ENSO event}

It was found that both PNA and WP patterns represented the $\mathrm{AL}$ variations better. The pioneering work by Kodera (1998) pointed out the importance of El Niño/Southern Oscillation (ENSO) events for the generation of both teleconnection patterns. Since then, numerous authors have emphasized that the intensity variation of AL is also related to the ENSO events (Hanawa et al. 1989; Zhang et al. 1996). The respective correlation coefficients of the Niño-3.4 index (SST anomalies averaged for $5^{\circ} \mathrm{S}-5^{\circ} \mathrm{N}, 170 \mathrm{~W}^{\circ}-120^{\circ} \mathrm{W}$; Trenberth 1997) regarded as an indicator of ENSO event versus the PNA and WP indices are 0.41 and 0.46 , the values

(b) Latitudinal position vs. SLP

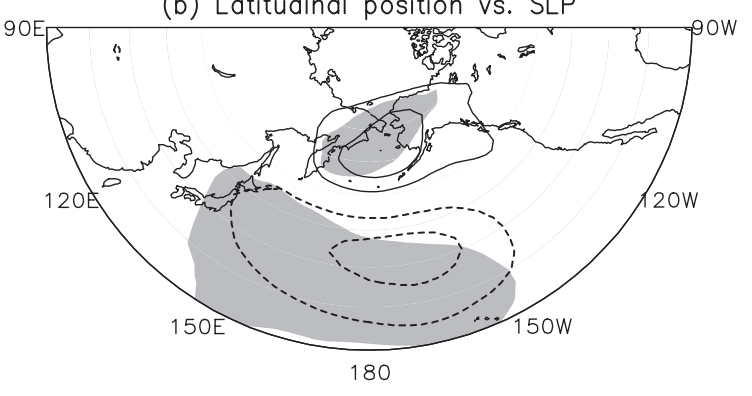

(d) WP vs. SLP

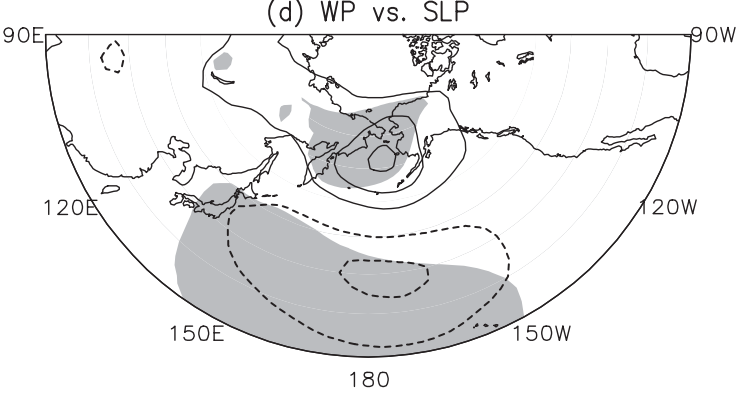

Fig. 5. Regression maps of the winter SLP anomaly field for normalized time series of (a) intensity, (b) latitudinal position of AL, (c) PNA index, and (d) WP index. The signs of the intensity time series and the SLP anomaly field are reversed for the same reason as that of NPI. Solid (dashed) lines show positive (negative) values. The contour interval is $1 \mathrm{hPa}$. Zero contours are omitted. Shading shows regions with values greater than a $1 \%$ significance level. 

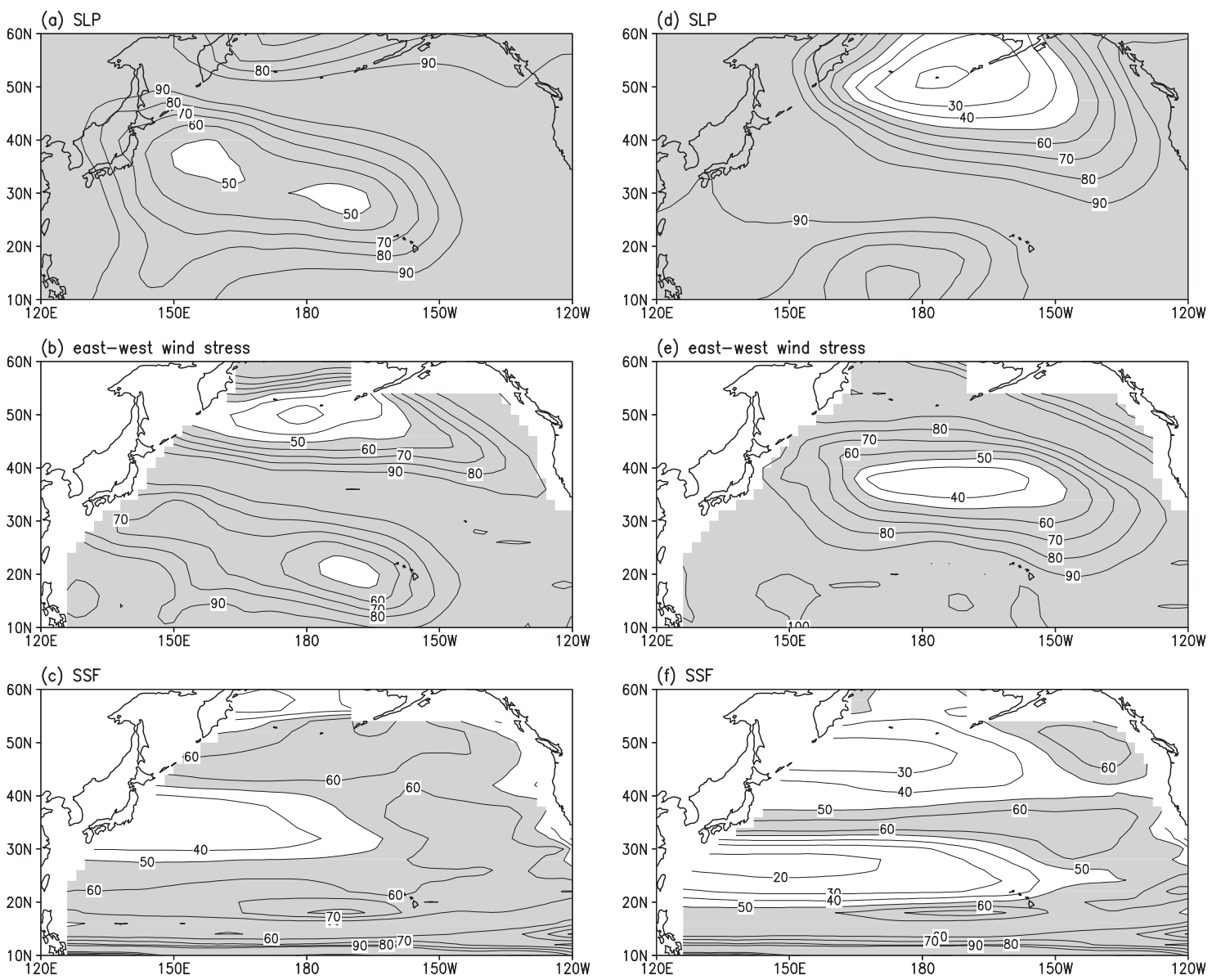

Fig. 6. Fraction of variance after removing the signals associated with the AL north-south shift for total variance (\%): (a) SLP, (b) east-west wind stress, and (c) SSF. Contour interval is $10 \%$. Shading denotes regions with values greater than 50\%. (d), (e), and (f) As in (a), (b), and (c), but for after removing the signals related to the AL intensity variation, respectively.

of which exceed a 5\% significance level. Notwithstanding, it is difficult to conclude that these teleconnection patterns depend only on the ENSO events because the correlation coefficients are not remarkably high. Herein, we explore behaviors of teleconnection patterns at individual ENSO events. Both El Niño and La Niña are defined by a continued pattern of $+/-0.4^{\circ} \mathrm{C}$ for 6 months or more (Trenberth 1997). Upon examination of Fig. 4, both the PNA and WP pattern indices tend to take positive peaks in the El Niño years and negative peaks in the La Niña years. However, not all the peaks are associated with the ENSO events. For instance, although the PNA index shows the largest positive peak in 1977 and the largest negative peak in 1956, and the WP index takes the largest negative peak in 1963, ENSO event did not occur in these years. The PNA index takes a negative extreme in 1969 of the El Niño year, and WP shows a positive extreme in 1999 of the La Niña year. These results imply that other mechanisms in addition to the ENSO events work for the generation of teleconnection patterns.

\section{Impact of AL activities on the upper ocean field}

\subsection{Oceanic gyre response to the AL activity}

To describe features associated with the intensity variation and latitudinal shift of $A L$, we perform a composite analysis for SLP, east-west wind stress, and Sverdrup stream function (SSF) field. The SSFs can be regarded as currents of wind driven circulation, i.e., the Sverdrup-balanced flow in the interior ocean, under the assumption of a linearbarotropic response of the ocean to WSC field. In 

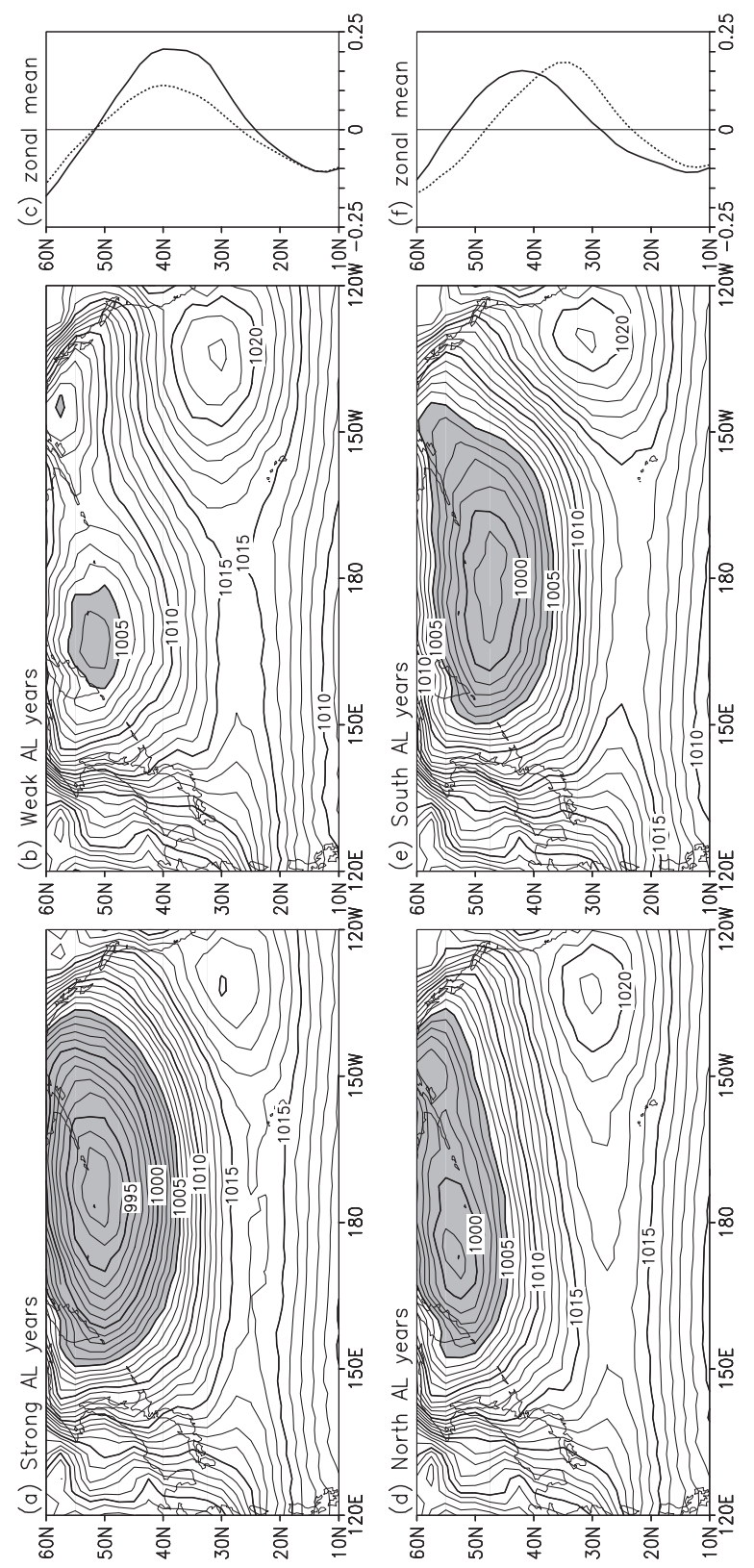

Fig. 7. Composite maps of winter SLP in (a) strong AL years [1970, 1977, 1978, 1981, 1983, 1987, 1998, 2001, 2003, 2004], (b) weak AL years $[1950,1954,1956,1957$, 1971, 1972, 1982], (d) north AL years [1951, 1953, 1958, 1960, 1966, 1969, 1979, 1990, 1992, 1998, 2001, 2002], and (e) south AL years [1957, 1962, 1963, 1968, 1974, 1981, 1984, 1991, 1997]. The contour interval is $1 \mathrm{hPa}$. Shading denotes regions with values less than $1005 \mathrm{hPa}$. (c) The latitudinal distribution of zonal mean $\left[150^{\circ} \mathrm{E}-170^{\circ} \mathrm{W}\right]$ east-west wind stress the real ocean, because of delayed ocean adjustment processes attributable to baroclinic Rossby wave propagation, we cannot expect such a simultaneous response. Nevertheless, such information would be useful.

We define four categories of strong AL, weak AL, north AL, and south AL years. The strong (weak) AL years are determined as those when the normalized intensity time series exceeds plus (minus) one standard deviation. Here, the sign of the intensity time series is reversed for the same reason as that of NPI. Although the intensity time series has the substantial trend as shown in Fig. 2a, we show results of strong AL and weak AL years defined by the raw time series including the trend, because almost identical results were obtained using the de-trended time series. Using an identical procedure, north and south AL years are determined from the normalized latitudinal position time series. In performing a composite analysis at the strong $\mathrm{AL}$ and weak AL years, it is needed to remove the signals related to the meridional shift of $\mathrm{AL}$ in order to evaluate effects of AL intensity variation properly. Therefore, we prepare dataset of SLP, east-west wind stress, and SSF, in which the signals of AL north-south shift are eliminated using a regression analysis. Figures $6 \mathrm{a}-\mathrm{c}$ shows a fraction of variance of prepared dataset for total variance. The prepared SLP has large signals at the region north of $40^{\circ} \mathrm{N}$, and the east-west wind stress shows large amplitudes in the latitudinal band of about $40^{\circ} \mathrm{N}$. The large signals of SSF are distributed in both subtropical (about $20^{\circ} \mathrm{N}$ ) and subpolar gyres (about $50^{\circ} \mathrm{N}$ ). In performing the analysis at the north AL and south AL years, we use dataset removed effects of AL intensity variation using an identical procedure. The dominant signals of prepared SLP are distributed in the zonal band of $25^{\circ} \mathrm{N}-35^{\circ} \mathrm{N}$ (Fig. 6d) and a map of east-west wind stress shows a north-south dipole pattern, whose boundary lies along the latitude of about $40^{\circ} \mathrm{N}$ (Fig. 6e). The SSF has large signals along the zonal band of about $30^{\circ} \mathrm{N}-40^{\circ} \mathrm{N}$.

Figures 7a, b respectively portray the SLP distributions of the strong AL and weak AL years. In the strong AL years, the central pressure strengthens by about $10 \mathrm{hPa}$ compared to that in the weak

$\left(\mathrm{kg} \mathrm{m}^{-1} \mathrm{~s}^{-2}\right)$ : the strong AL years (solid line) and the weak AL years (dashed line). (f) As (c) but for the north AL years (solid line) and the south AL years (dashed line). 
AL years. The area of the pressure system less than $1005 \mathrm{hPa}$ expands, as described in past works (Trenberth and Hurrell 1994; Beamish et al. 1997). Consequently, the SLP field in the strong AL years has a large meridional gradient in the zonal band of $35^{\circ} \mathrm{N}-45^{\circ} \mathrm{N}$. This indicates strengthening of surface westerlies. Actually, its maximum of zonal mean east-west wind stress becomes about twice that of the weak AL years (Fig. 7c). As described above, the $\mathrm{AL}$ central position in the strong $\mathrm{AL}$ years shifts eastward by $20^{\circ}$ in longitude compared with that in the weak AL years.

Figures 7d, e respectively depict the SLP distributions of the north and south AL years. No significant difference was found in the intensity and area of $\mathrm{AL}$ between the two categories. In the north $\mathrm{AL}$ years, the AL central position shifts northward by $10^{\circ}$ in latitude compared with that in the south $\mathrm{AL}$ years. Consequently, although the westerlies have almost equal magnitude, the position of the maximum shifts northward by $10^{\circ}$ (Fig. 7f).

The analyses described above show that the intensity variation and longitudinal shift of AL correspond to a change in magnitude of the westerlies; the latitudinal shift does so to the meridional shift of the westerlies centered around $38^{\circ} \mathrm{N}$.

Variations of the westerlies are expected that yield different oceanic responses in the upper ocean field. Here, we specifically examine the SSF fields. Figures $8 \mathrm{a}-\mathrm{c}$ respectively portray the SSF for the
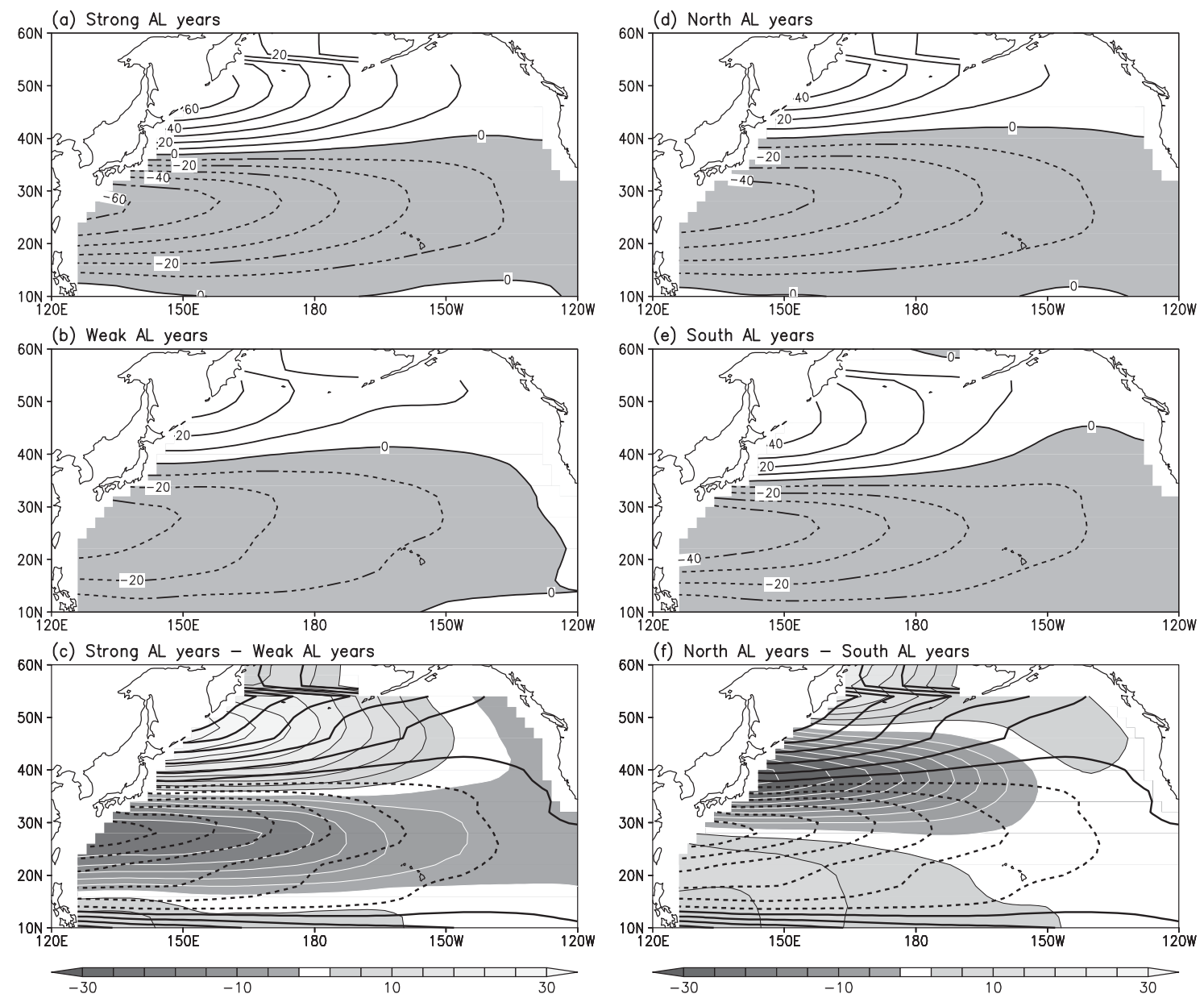

Fig. 8. Composite maps of winter SSF in (a) strong AL years, (b) weak AL years, (d) north AL years, and (e) south AL years. The contour interval is $10 \mathrm{~Sv}\left(\mathrm{~Sv}=10^{6} \mathrm{~m}^{3} \mathrm{~s}^{-1}\right)$; shading denotes a negative value. (c) The difference of SSF between the strong AL years and weak AL years. The contour shows the climatological mean SSF. Zero contours are omitted. The contour interval is $10 \mathrm{~Sv}$. (f) As in (c) but for the north AL years and south AL years. 


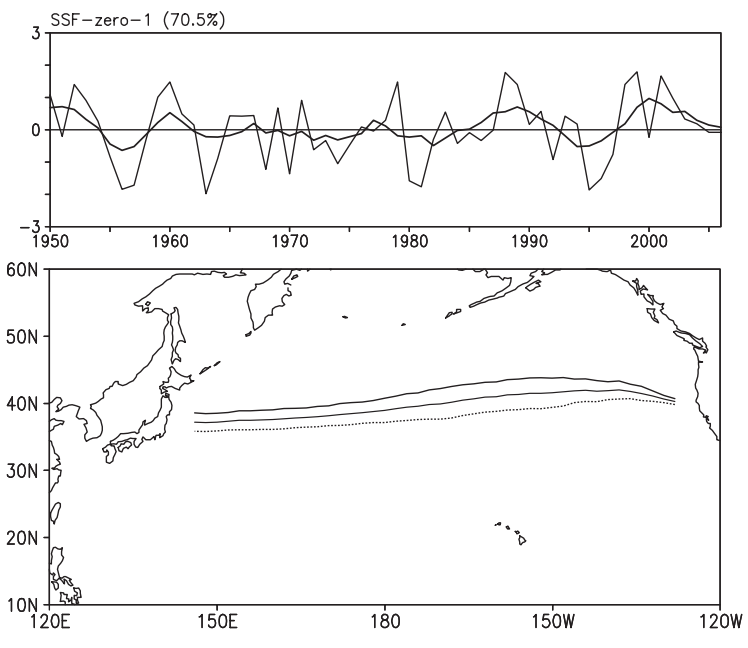

Fig. 9. The first EOF mode of SSF-zero line. (Upper panel) Time coefficient. The thick line denotes the 5-year running mean. The percentage of explained variance is shown in the parentheses. (Lower panel) The thick line represents the mean location of the SSF-zero line. The solid line shows regression coefficients of the SSF-zero line variation for the time coefficient. The dashed line shows a reversed sign of the solid line.

strong AL and weak AL years and their difference. In the strong AL years, the maximum values of SSF increase at both subtropical and subpolar gyres: their increase is more than twice at the both gyres, which confirms the findings by Qiu (2003) and Ishi and Hanawa (2005).

Figures $8 \mathrm{~d}-\mathrm{f}$ respectively portray the SSF for the north AL and south AL years and their differences. In the north AL years, the gyre boundary designated by the SSF-zero line shifts northward by $10^{\circ}$ in latitude compared to that in the south AL years. However, in both categories, the maximum values of SSF take almost identical values at the both gyres. These features reflect the conditions of the westerlies in terms of the magnitude (nearly equal) and location (about $10^{\circ}$ northward shift).

We investigate temporal behaviors of the SSFzero line to provide further evidence for the meridional shift of gyre boundary. To extract a largescale variation, we perform an EOF analysis adopting a correlation matrix method for the SSFzero line from $146^{\circ} \mathrm{E}$ to $128^{\circ} \mathrm{W}$ which is detected through the analysis period (Fig. 9). The first mode clearly illustrates a meridional shift of the gyre boundary across the whole North Pacific. The time
Table 2. Correlation coefficients of time series of winter intensity, longitudinal position, and latitudinal position of AL, PNA, and WP indices, to the time coefficient of the SSF-zero-1. The sign of the intensity time series is reversed for the same reason as that of NPI. Bold typeface numerals signify those exceeding a $1 \%$ significance level $(+/-0.47)$.

\begin{tabular}{|c|c|c|c|c|c|}
\hline & Intensity & $\begin{array}{c}\text { Longitu- } \\
\text { dinal } \\
\text { position }\end{array}$ & $\begin{array}{l}\text { Latitu- } \\
\text { dinal } \\
\text { position }\end{array}$ & PNA & WP \\
\hline SSF-zero-1 & 0.07 & 0.06 & 0.59 & -0.06 & 0.69 \\
\hline
\end{tabular}

series of its amplitude represents the decadal scale variation; it has a correlation only with the latitudinal shift of $\operatorname{AL}(R=0.59$, see Table 2). Because the first mode (SSF-zero-1) accounts for about $70 \%$ of total variance, variation of the gyre boundary is related strongly to the latitudinal shift of AL.

\subsection{Impact of the north-south shift of AL on SST variation in the Kuroshio-Oyashio Extension region}

In this study, we newly identified the northsouth shift of AL on the decadal timescale. This caused the meridional shift of the gyre boundary represented by the SSF-zero line. However, the result was obtained under the assumption of linearbarotropic response, and might indicate the SSF for the annual and long-term mean as some constraint for the oceanic gyre. Therefore, it is difficult to be convinced of year-to-year variations.

Recent studies have attempted to elucidate longterm oceanic variations in the Kuroshio-Oyashio Extension (KOE) region. Numerous authors have suggested that the variations resulted from the wind-induced Rossby wave (e.g., Seager et al. 2001; Schneider et al. 2002; Taguchi et al. 2007). We investigate how the AL north-south shift influences the winter mean (December-February) SST variation in the KOE region (hereinafter abbreviated as KOE-SST) to reemphasize the importance of the north-south shift on the upper ocean field.

Figure 10 presents the KOE-SST variation averaged for $\left[36^{\circ} \mathrm{N}-40^{\circ} \mathrm{N}, 145^{\circ} \mathrm{E}-160^{\circ} \mathrm{E}\right]$ and a wavelet analysis result. Two dominant timescales are identifiable: interdecadal and decadal. Past works have shown that the KOE-SST variation on the interdecadal timescale is associated with the AL activity, using NPI showing a change in the magnitude of AL (Miller and Schneider 2000; Hanawa and Kamada 2001). On the other hand, although it is 

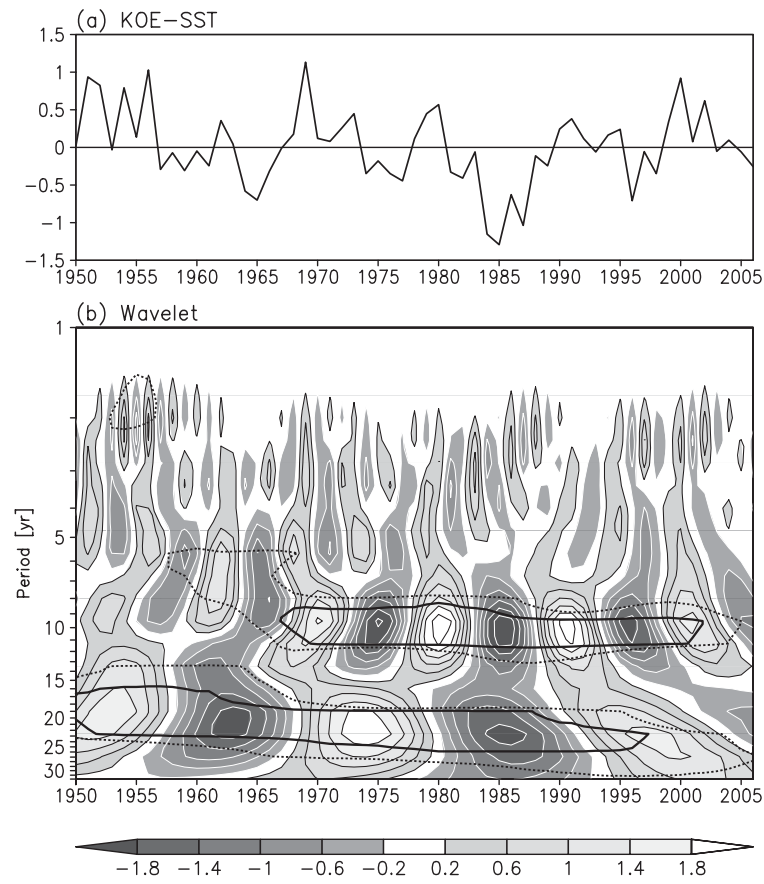

Fig. 10. (a) Winter SST anomalies $\left({ }^{\circ} \mathrm{C}\right)$ averaged within the $\mathrm{KOE}$ region $\left[36^{\circ} \mathrm{N}-40^{\circ} \mathrm{N}\right.$, $145^{\circ} \mathrm{E}-160^{\circ} \mathrm{E}$. (b) As in Fig. 3, but for the KOE-SST anomalies.

reported that decadal-scale variations in the KOE region are caused by the forcing of the large-scale wind stress field (Qiu 2003; Qiu and Chen 2005), it has not been clarified how atmospheric forcing is triggered. Here, we can point out interesting features related to the behavior of the significant periodic band around the decadal timescale. The significance band tends to lengthen with time: with about a 7-year period before the 1970s and with about an 11-year period thereafter. Surprisingly, identical behavior is apparent in the north-south shift of AL, as displayed in Fig. 3c. Therefore, it is expected that the latitudinal shift of AL forces the KOESST variations.

To clarify the above speculation quantitatively, it is very useful to adopt the $1 \frac{1}{2}$-layer reduced gravity model that governs the large-scale baroclinic ocean response to surface-wind forcing. Under long-wave approximation, the linear vorticity equation of the model is

$$
\frac{\partial h}{\partial t}-c_{R} \frac{\partial h}{\partial x}=-\frac{g^{\prime} \vec{k} \cdot \nabla \times \vec{\tau}}{\rho_{0} g f}
$$

where $h$ is the sea surface height $(\mathrm{SSH}), c_{R}$ is the speed of the long baroclinic Rossby waves, $g^{\prime}$ is the reduced gravity $\left(2.7 \mathrm{~cm} \mathrm{~s}^{-2}\right), \rho_{0}$ is the reference density, $f$ is the Coriolis parameter, $\vec{k}$ is the unit vector in the vertical direction, and $\vec{k} \cdot \nabla \times \vec{\tau}$ is the curl of the wind stress vector. Integrating Eq. (1) from the eastern boundary $\left(x_{e}\right)$ along the baroclinic Rossby wave characteristic, we obtain the following:

$$
\begin{aligned}
h(x, y, t)= & h\left(x_{e}, y, t+\frac{x-x_{e}}{c_{R}}\right)+\frac{g^{\prime}}{\rho_{0} g f c_{R}} \int_{x_{e}}^{x} \vec{k} \cdot \nabla \\
& \times \tau\left(x^{\prime}, y, t+\frac{x-x^{\prime}}{c_{R}}\right) d x^{\prime}
\end{aligned}
$$

We use wind stress data to hindcast the $h(x, y, t)$ field from Eq. (2). Along the eastern boundary, $h\left(x_{e}, y, t\right)=0$ is assumed, according to $\mathrm{Fu}$ and Qiu (2002) and Qiu (2003). The latitude-dependent baroclinic Rossby wave speed $c_{R}$ is determined based on results of past works (Tai and White 1990; Fu and Chelton 2001; Qiu 2003) $\left(c_{R}=2.3 \mathrm{~cm} \mathrm{~s}^{-1}\right.$ at $38^{\circ} \mathrm{N}$ ).

Figure 11a displays the time-longitude diagram of the modeled $\mathrm{SSH}$ anomalies along $38^{\circ} \mathrm{N}$ (henceforth, normal model). Most SSH signals in the west can be traced from the eastern North Pacific. The modeled SSH signals clearly represent decadal-scale variation. Here, we examine whether or not the variations are caused by the north-south shift of AL. Figure $11 \mathrm{~b}$ depicts an output obtained from wind stress regressed the signals of AL north-south shift (henceforth, AL north-south shift model). As observed in the normal model, the decadal signals are found obviously. We compare behaviors at a western grid $\left(145^{\circ} \mathrm{E}\right)$ between these two models. The correlation coefficient is 0.54 , the value of which exceeds a $1 \%$ significance level, and furthermore the variance of AL north-south shift model accounts for about $55 \%$ of total variance of normal model. This AL north-south shift model well reproduces the variations of normal model, and it is pointed out that the Rossby wave along $38^{\circ} \mathrm{N}$ is excited by the meridional shift of AL. It is worth noting where large signals are formed in the AL north-south shift model. The formation region is the central North Pacific around $170^{\circ} \mathrm{W}$ : positive signals in the 1950s, early 1970s, early 1990s, and early 2000 s and negative signals in the late 1960s, late 1980s, and late 1990s. The former periods correspond to the northern shift years of AL; the latter correspond to southern shift years (Fig. 2c). Appar- 

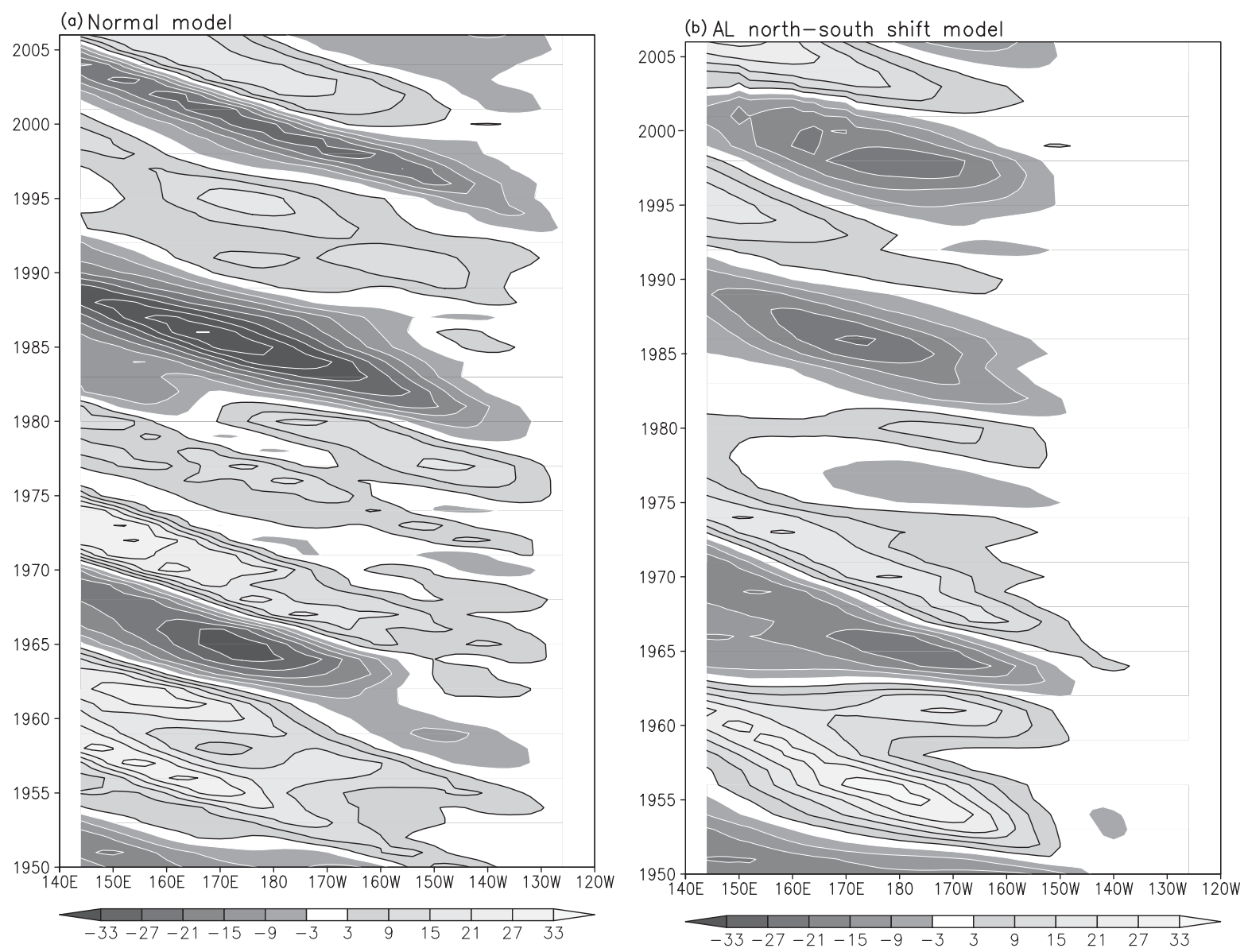

Fig. 11. Modeled SSH anomalies along $38^{\circ} \mathrm{N}$ from the wind-driven hindcast model as a function of time and longitude: (a) normal model and (b) AL north-south shift model. The contour interval is $6 \mathrm{~cm}$.

ently, the generation area of large signals depends strongly on the location of AL.

Next, we investigate a relation with the KOESST. The correlation coefficient between the KOESST variation and the AL north-south shift model variation averaged within the KOE region [longitudinal band of $145^{\circ} \mathrm{E}$ to $160^{\circ} \mathrm{E}$ ] is 0.53 , the value of which exceeds a $1 \%$ significance level. This fact implies that the oceanic Rossby wave formed as a result of the baroclinic response for the north-south shift of AL gives a significant impact on the KOESST variation.

\section{Summary and remarks}

In this study, we investigated temporal variations of AL central position defined as the SLP minimum within the region of $\left[30^{\circ} \mathrm{N}-60^{\circ} \mathrm{N}, 150^{\circ} \mathrm{E}-150^{\circ} \mathrm{W}\right]$ during winter. Results show two different types of AL activities. One type of activity is the longitudi- nal shift accompanying intensity variation with the interdecadal timescale of about 20 years. The intensity variation is associated with the PNA pattern, as described by Trenberth and Hurrell (1994); it forces both subtropical and subpolar gyres to spin-up or spin-down simultaneously, as pointed out by Ishi and Hanawa (2005). In the strengthening (weakening) phase of $\mathrm{AL}$, the $\mathrm{AL}$ is located east (west) in longitude, westerlies strengthen (weaken), and both gyres are forced to spin-up (spin-down) simultaneously. A second type of activity is the latitudinal shift with a decadal timescale of about 10 years; this timescale variation of AL activity was first identified in this study. The latitudinal shift is related to the WP pattern. This latitudinal shift, which is independent from the intensity variation and longitudinal shift, causes a meridional shift of the gyre boundary. In the northward (southward) phase of AL, the westerlies shift northward (south- 
ward) and the gyre boundary moves northward (southward).

We evaluated the roles of north-south shift of AL on the upper ocean field, by using the winddriven hindcast model. It was found that the oceanic Rossby wave formed as a result of the baroclinic response for the latitudinal shift of AL gave a significant impact on the KOE-SST variation. Recent analyses of observed data have suggested the existence of ocean to atmosphere feedback in the KOE region (Nonaka and Xie 2003; Tanimoto et al. 2003; Tokinaga et al. 2006). Therefore, it is strongly suggested that the understanding of north-south shift of AL is crucial to revealing an air-sea coupled system in the mid-latitude and to clarifying the decadal-scale oceanic responses.

The physical processes such as generation, maintenance, and decay of WP are not clear at present, although the importance of ENSO event was pointed in the past works (e.g., Kodera 1998). In this study, it was found that the WP does not always occur in the ENSO years. This implies that other mechanism in addition to ENSO work for the WP pattern. We must reveal the dynamical mechanisms of WP as a next step for the further understanding of AL activities.

We assure that the NPI, ALPI, and PNA index are good indicators of the AL intensity variation. The usage of the NPI and ALPI has greatly advanced the understanding of interdecadal-scale oceanic variation in the North Pacific sector (Hanawa and Kamada 2001; Schneider and Cornuelle 2005; Sugimoto and Hanawa 2007). However, as we have found through results of the present study, these indices cannot represent the latitudinal shift of AL. The salient contribution of this study is that the WP index is demonstrably the best indicator of latitudinal shift. We believe that results of this study will attract attention to decadal-scale variation in the North Pacific sector and the role of WP teleconnection pattern on oceanic variations. Furthermore, we expect that elucidation of the climate system in the North Pacific can be greatly accelerated through widespread use of the WP index.

\section{Acknowledgements}

The authors express their sincere gratitude to the members of the Physical Oceanography Group at Tohoku University for their useful discussion. A number of valuable comments given by two reviewers and a useful comment by the Editor (Dr. Y. Tanimoto) are appreciated. The first author
(SS) was financially supported by Research Fellowships of the Japan Society for the Promotion of Science (JSPS) for Young Scientists. The second author $(\mathrm{KH})$ was financially supported by the Japanese Fisheries Agency and by the 21st Century Center-of-Excellence (COE) Program at Tohoku University.

\section{References}

Barnston, A. G., and R. E. Livezey, 1987: Classification, seasonality and persistence of low-frequency atmospheric circulation pattern. Mon. Wea. Rev., 115, 1083-1126.

Beamish, R. J., C. E. Neville, and A. J. Cass, 1997: Production of Fraser River sockeye salmon (Oncorhynchus nerka) in relation to decadal-scale changes in the climate and the ocean. Can. J. Fish. Aquat. Sci., 54, 543-554.

Davis, R., 1976: Predictability of sea surface temperature and sea level pressure anomalies over the North Pacific Ocean. J. Phys. Oceanogr., 6, 249-266.

Ebbesmeyer, C. C., and Coauthors, 1991: 1976 step in the Pacific climate: Forty environmental changes between 1968-75 and 1977-84. Proc. Seventh Annual Pacific Climate Workshop, Pacific Grove, CA, California Dept. of Water Resources, Interagency Ecology Studies Program Rep, 26, 115126.

Fu, L. L., and D. B. Chelton, 2001: Large-scale ocean circulation. Satellite Altimetry and Earth Sciences, L. L. Fu and A. Cazenava, Eds., Academic Press, 133-169.

Fu, L. L., and B. Qiu, 2002: Low-frequency variability of the North Pacific Ocean: The roles of boundaryand wind-driven baroclinic Rossby waves. J. Geophys. Res., 107, 3220, doi:10.1029/2001JC001131.

Hanawa, K., Y. Yoshikawa, and T. Watanabe, 1989: Composite analyses of wintertime wind stress vector fields with respect to SST anomalies in the western North Pacific and the ENSO events: Part II. ENSO composite. J. Meteor. Soc. Japan, 67, 835-845.

Hanawa, K., and J. Kamada, 2001: Variability of core layer temperature (CLT) of North Pacific subtropical mode water. Geophys. Res. Lett., 28, 22292232.

Ishi, Y., and K. Hanawa, 2005: Large-scale variability of wintertime wind stress curl field in the North Pacific and their relation to atmospheric teleconnection patterns. Geophys. Res. Lett., 32, L10607, doi:10.1029/2004GL022330.

Kalnay, E., and Coauthors, 1996: The NCEP/NCAR 40year reanalysis project. Bull. Amer. Meteor. Soc., 77, 437-471.

Kendall, M. G., 1938: A new measure of rank correlation. Biometrika, 30, 81-93. 
Kodera, K., 1998: Consideration of the origin of the different midlatitude atmospheric responses among El Niño events. J Meteor. Soc. Japan, 76, 347-361.

Latif, M., and T. P. Barnett, 1996: Decadal climate variability over the North Pacific and North America: Dynamics and predictability. J. Climate, 9, 24072423.

Mantua, N. J., S. R. Hare, Y. Zhang, J. M. Wallace, and R. Francis, 1997: A Pacific interdecadal climate oscillation with impacts on salmon production. Bull. Amer. Meteor. Soc., 78, 1069-1079.

Miller, A. J., and N. Schneider, 2000: Interdecadal climate regime dynamics in the North Pacific Ocean: Theories, observations and ecosystem impacts. Progress in Oceanogr., 47, 355-379.

Minobe, S., 1997: A 50-70 year climatic oscillation over the North Pacific and North America. Geophys. Res. Lett., 24, 683-686.

Minobe, S., 1999: Resonance in bidecadal and pentadecadal climate oscillations over the North Pacific: Role in climate regime shift. Geophys. Res. Lett., 26, 855-858.

Nitta, T., and S. Yamada, 1989: Recent warming of tropical sea surface temperature and its relationship to the Northern Hemisphere circulation. J. Meteor. Soc. Japan, 67, 375-382.

Nonaka, M., and S. -P. Xie, 2003: Covariations of sea surface temperature and wind over the Kuroshio and its extension: Evidence for ocean-toatmosphere feedback. J. Climate, 16, 1404-1413.

Overland, J. E., J. M. Adams, and N. A. Bond, 1999: Decadal variability of the Aleutian Low and its relation to high-latitude circulation. J. Climate, 12, 1542-1548.

Polovina, J. J., G. T. Mitchum, and G. T. Evans, 1995: Decadal and basin-scale variation in mixed layer depth and the impact on biological production in the Central and North Pacific, 1960-1988. DeepSea Res., 42, 1701-1716.

Qiu, B., 2003: Kuroshio extension variability and forcing the Pacific decadal oscillation: Responses and potential feedback. J. Phys. Oceanogr., 33, 24652482.

Qiu, B., and S. Chen, 2005: Variability of the Kuroshio Extension jet, recirculation gyre, and mesoscale eddies on decadal time scales. J. Phys. Oceanogr., 35, 2090-2103.

Raible, C. C., and Coauthors, 2005: Northern Hemisphere trends of pressure indices and atmospheric circulation patterns in observations, reconstructions, and coupled GCM simulations. J. Climate, 18, 3968-3982.

Rodionov, S. N., J. E. Overland, and N. A. Bond, 2005: The Aleutian Low and winter climate conditions in the Bering Sea: Part I. Classification. J. Climate, 18, 160-177.
Rogers, J. C., 1981: The North Pacific oscillation. J. Climatol., 1, 39-57.

Schneider, N., A. J. Miller, and D. W. Pierce, 2002: Anatomy of North Pacific decadal variability. $J$. Climate, 15, 586-605.

Schneider, N., and B. D. Cornuelle, 2005: The forcing of the Pacific decadal oscillation. J. Climate, 18, 4355-4373.

Seager, R., Y. Kushnir, N. H. Naik, M. A. Cane, and J. Miller, 2001: Wind-driven shifts in the latitude of the Kuroshio-Oyashio extension and generation of SST anomalies on decadal timescales. J. Climate, 14, 4149-4165.

Smith, T. M., and R. W. Reynolds, 2004: Improved extended reconstruction of SST (1854-1997). J. Climate, 17, 2466-2477.

Sugimoto, S., and K. Hanawa, 2007: Impact of remote reemergence of the subtropical mode water on winter SST variation in the central North Pacific, $J$. Climate, 20, 173-186.

Taguchi, B., S. -P. Xie, N. Schneider, M. Nonaka, H. Sasaki, and Y. Sasaki, 2007: Decadal variability of the Kuroshio Extension: Observations and an eddy-resolving model hindcast. J. Climate, 20, 2357-2377.

Tai, C. T., and W. B. White, 1990: Eddy variability in the Kuroshio Extension as revealed by GEOSAT altimetry: Energy propagation away from the jet, Reynolds stress, and seasonal cycle. J. Phys. Oceanogr., 20, 1761-1777.

Tanimoto, Y., H. Nakamura, T. Kagimoto, and S. Yamane, 2003: An active role of extratropical sea surface temperature anomalies in determining anomalous turbulent heat flux. J. Geophys. Res., 108, 3304, doi:10.1029/2002JC001750.

Tokinaga, H., Y. Tanimoto, M. Nonaka, B. Taguchi, T. Fukamachi, S. -P. Xie, H. Nakamura, T. Watanabe, and I. Yasuda, 2006: Atmospheric sounding over the winter Kuroshio Extension: Effect of surface stability on atmospheric boundary layer structure. Geophys. Res. Lett., 33, L04703, doi:10.1029/ 2005 GL025102.

Trenberth, K. E., 1990: Recent observed interdecadal climate changes in the Northern Hemisphere. Bull. Amer. Meteor. Soc., 71, 988-993.

Trenberth, K. E., and J. W. Hurrell, 1994: Decadal atmosphere-ocean variations in the Pacific. Clim. Dyn., 9, 303-319.

Trenberth, K. E., 1997: The definition of El Niño. Bull. Amer. Meteor. Soc., 78, 2771-2777.

Uppala, S. M., and Coauthors, 2005: The ERA-40 reanalysis. Quart. J. Roy. Meteor. Soc., 131, 29613012 .

Walker, G. T., and E. W. Bliss, 1932: World weather V. Mem. Roy. Meteor. Soc., 4, 53.

Wallace, J. M., and D. S. Gutzler, 1981: Teleconnections 
in the geopotential height field during the Northern Hemisphere winter. Mon. Wea. Rev., 109, 784812.

Yasuda, T., and K. Sakurai, 2006: Interdecadal variability of the sea surface height around Japan.
Geophys. Res. Lett., 33, L01605, doi:10.1029/ 2005GL024920.

Zhang, Y., M. Wallace, and N. Iwasaka, 1996: Is climate variability over the North Pacific a linear response to ENSO?, J. Climate, 9, 1468-1478. 